\title{
Algorithms of control parameters selection for automation of FDM 3D printing process
}

\author{
Pawet Kogut, Krzysztof Kalinowski ${ }^{*}$ Cezary Grabowik, Grzegorz Ćwikła, \\ and Iwona Paprocka \\ Silesian University of Technology, Faculty of Mechanical Engineering, Institute of Engineering \\ Processes Automation and Integrated Manufacturing Systems, Konarskiego 18A, 44-100 Gliwice, \\ Poland
}

\begin{abstract}
The paper presents algorithms of control parameters selection of the Fused Deposition Modelling (FDM) technology in case of an open printing solutions environment and 3DGence ONE printer. The following parameters were distinguished: model mesh density, material flow speed, cooling performance, retraction and printing speeds. These parameters are independent in principle printing system, but in fact to a certain degree that results from the selected printing equipment features. This is the first step for automation of the 3D printing process in FDM technology.
\end{abstract}

\section{Introduction}

3D printing (also known as a spatial printing) belongs to additive manufacturing group of techniques, and opposite to the machining processes - three-dimensional physical objects, based on a computer model, are "formed out of nothing" [1-3]. In additive process object is created step by step by successive addition of small pieces of material, thin layers [4,5].

Originally, 3D printing was one of rapid prototyping techniques used to build moulds and prototypes themselves. However, the development of this technology that affects the achievement of better accuracy of printouts caused that 3D printing has become a method of receiving ready-made objects which are characterized by very good properties [6]. The possibilities of using spatial printers mainly depend on production methods [7], materials, which are available on the market and the volume of the printer. In practice, all 3D printing methods are similar because they form the object layer by layer in order to create complex shapes. The difference, however, is in the way of creation those layers and the material which is used in the process.

The popularity of FDM technology derives from its cheapness and wide availability. It is also the most popular due to the number of printers which are available on the market [8]. This method is based on building the model layer by layer. Each layer consists of thin lines. The lines are applied according to the generated G-Code commands. After applying all lines on the given layer, the head of the printer (hotend) raises the value of the next layer thickness or the heatbed moves down, depending on the type of the printer.

\footnotetext{
*Corresponding author: krzysztof.kalinowski@polsl.pl
} 


\section{Control parameters}

The process of creating 3D objects is under computer control. The proper selection of parameters allows controlling the $3 \mathrm{D}$ printing process and guarantee obtaining good quality models [9-11]. Currently, 3D printing is not fully automated but it can be changed in a few years. The key to success, an algorithm for selecting parameters that most influence the process of 3D printing should be made, because such parameters control this process. The creation of algorithms improves further work on the automation of the $3 \mathrm{D}$ printing process and can also be helpful for the today's operators of 3D printers.

The main aim of presented research is to find the most responsible parameters affecting the $3 \mathrm{D}$ printing process in FDM technology. These parameters are examined in order to present how they affect the final printout. Subsequently, the method of choosing optimal values for these parameters should be defined after making test prints. During the tests 3DGence ONE 3D printer was used.

In this study the parameters that significantly influence the final form of the printout were presented in Figure 1.

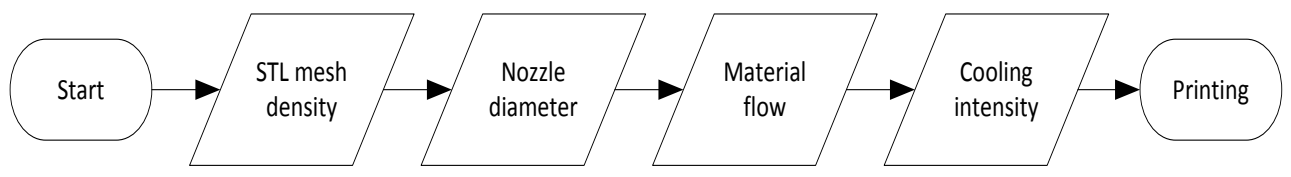

Fig. 1. The parameters' selection algorithm.

The parameters as material flow, percentage of cooling, retraction or printing speed can be customized in a slicer program designed to prepare the G-Code. The most important parameters are discussed below.

\subsection{Model mesh density}

The first step to print the object is its modelling in CAD software. For printing process, the model is translated to a grid triangle according to the STL (STereoLithography) standard. The main problem is choosing the proper mesh density for a model. It should be selected according to expected quality of final printout, with assumed level of details mapping [6,9].

Table 1 shows the three cases of mesh density: optimal, coarse and dense grid. The exampled test object consists of a cube, a pyramid, a cylinder with a hole and a ball and has $85 \times 25 \times 18 \mathrm{~mm}$. Case 1 presents correctly generated mesh. As it is seen, the grid mesh density occurs on curved surfaces such as the cylinder with a hole, the ball and rounded edges of the stand. The case 2 was generated with insufficient accuracy. The small mesh density caused the round elements such as a ball or a cylinder more "angular". The last case (3) was generated with the greatest available accuracy. The density of the grid was so large that the edges of the elements, which were close to each other, made the colour of the model locally black.

Table 2 summarizes the main differences between these models.

The difference between coarse and optimal grid is noticeable. The number of elements in optimal grid is more than twice bigger than in coarse grid. Also, the file size is more than twice greater but it is still acceptable. The volume is also increased. The smallest element size and the angle tolerance available in the program were used in dense grid. The number of elements in dense grid was more than 200x larger than in optimal. Also, the increase of the file size was huge. The value of the volume did not change significantly in contrast to the size of the file, which was unacceptable in this case. 
Table 1. Comparison of the mesh types.

\begin{tabular}{|l|l|l|l|}
\hline Case & Grid & Model after meshing \\
\hline 1 & Optimal & & \\
\hline 2 & Coarse & & \\
\hline 3 & Dense & & \\
\hline
\end{tabular}

Table 2. Comparison of the mesh types.

\begin{tabular}{|c|c|c|c|c|c|c|}
\hline Number & Mesh type & $\begin{array}{c}\text { Mesh } \\
\text { element }\end{array}$ & $\begin{array}{c}\text { Angle } \\
\text { tolerance }\end{array}$ & $\begin{array}{c}\text { Number of } \\
\text { elements }\end{array}$ & File size & $\begin{array}{c}\text { Model } \\
\text { volume }\end{array}$ \\
\hline Case 1 & Optimal grid & $0,0415 \mathrm{~mm}$ & $10^{\circ}$ & 2806 & $137 \mathrm{~KB}$ & $10,37 \mathrm{~cm}^{3}$ \\
\hline Case 2 & Coarse grid & $0,1076 \mathrm{~mm}$ & $30^{\circ}$ & 1164 & $58 \mathrm{~KB}$ & $10,33 \mathrm{~cm}^{3}$ \\
\hline Case 3 & Dense grid & $0,0045 \mathrm{~mm}$ & $0,5^{\circ}$ & 611350 & $21,9 \mathrm{MB}$ & $10,38 \mathrm{~cm}^{3}$ \\
\hline
\end{tabular}

\subsection{Diameter of the nozzle hole}

In most printer systems there's a possibility of use nozzles with different hole sizes. It is done manually by the operator but in the future can be automated. The appropriate diameter of the nozzle hole should be chosen for the specific project. The most popular hole sizes are between 0.1-0.5 mm. Smaller sizes allows achieving higher resolution and generally better surface quality of printed models. This is at the expense of much longer printing time due to the larger number of layers.

\subsection{Material flow}

The parameter of material flow enables correcting value of a fed filament during printing process. By increasing this flow the amount of extruded filament increases. The filament which is pushed by the extruder swells after leaving the nozzle. Each material behaves differently during printing. Therefore, proper value of the material flow must be chosen to get an accurate printout for each material [12-15].

An algorithm of a proper value selection of the material flow is shown in Figure 2. The first step is the measurement of the wall thickness in the calibration print. The value of the wall thickness should be equal to the diameter of the nozzle hole. The material flow can be 
also controlled during printing process for obtaining thickness of the wall smaller or bigger than the diameter of the nozzle hole.

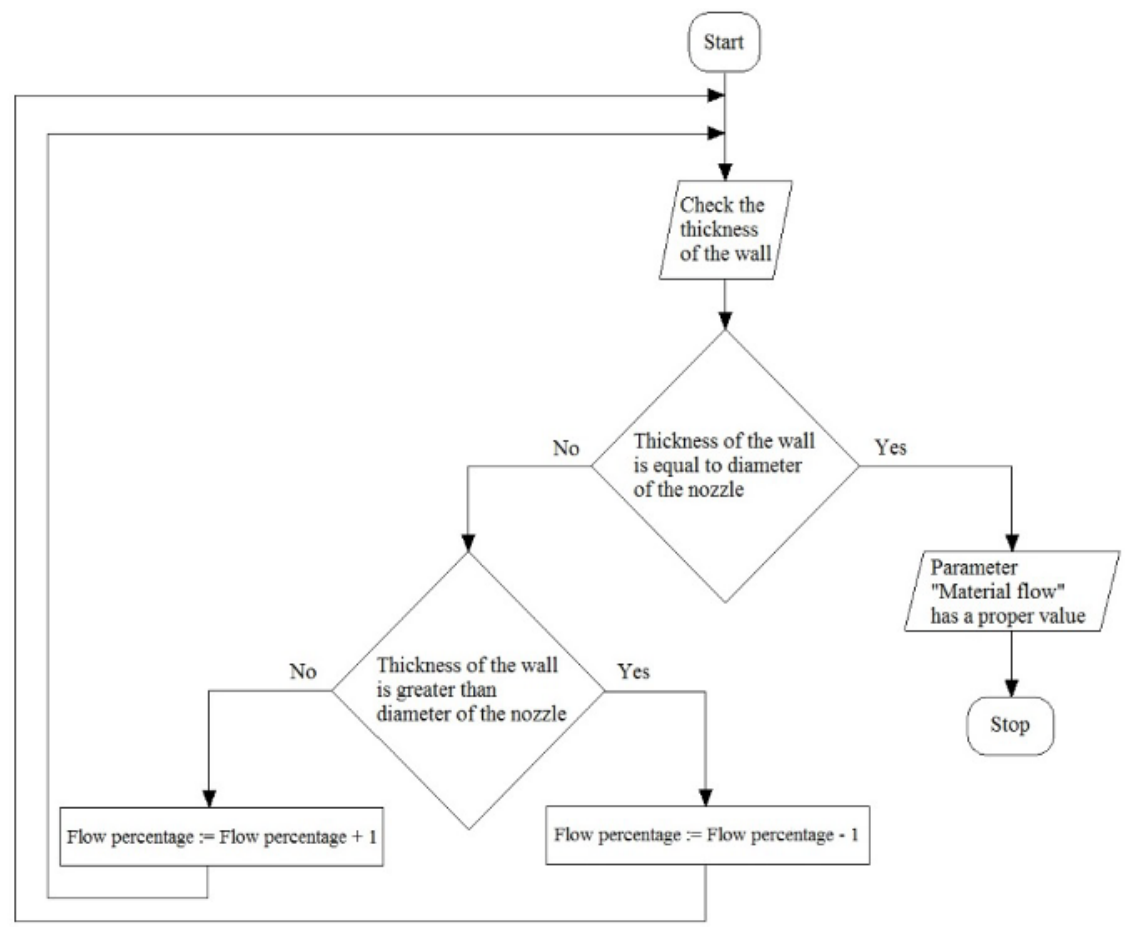

Fig. 2. The material flow algorithm.

\subsection{Cooling}

Cooling is one of the most important factors in FDM technology. Filament, heated in the printhead and extruded in the form of a plasticized line, requires cooling after laying. It would be seem that if the plastic path is not cooled properly it falls by gravity but insufficiently, cooled line tucks up (Figure 3). This is undesirable for two reasons: rolled up layers reduce the quality of the printout and the head can hit the rolled up layer during the application of the following layer.

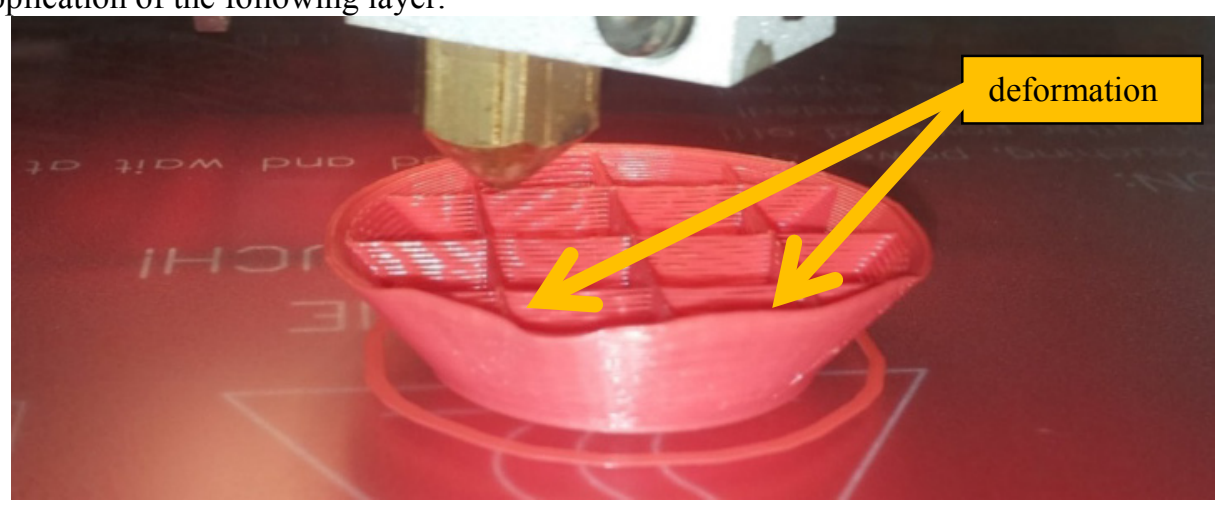

Fig. 3. The rolled up printout. 
In extreme cases, it can cause the detachment of the printout from the heated bed. Sided cooling can cause one side of the model print correctly but the other side is deformed (Figure 4). The poor quality of the printout is usually caused by rolling up and badly arranged layers. The Monkeyfab Prime (a) and 3DGence ONE (b) printers were used for this two test printouts. The application of double fans on both sides of the model is very helpful to achieve good quality of the printout - their placement prevents deformation of the layers on each side of the printout.

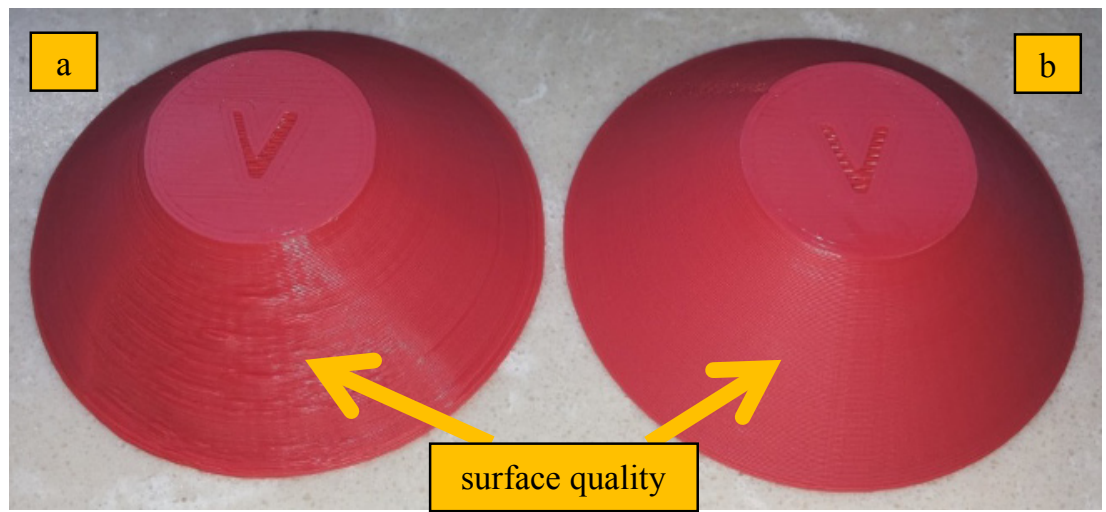

Fig. 4. The quality of surfaces using one side cooling and both sides cooling.

The proposed algorithm for selecting the cooling rate is presented in Figure 5.

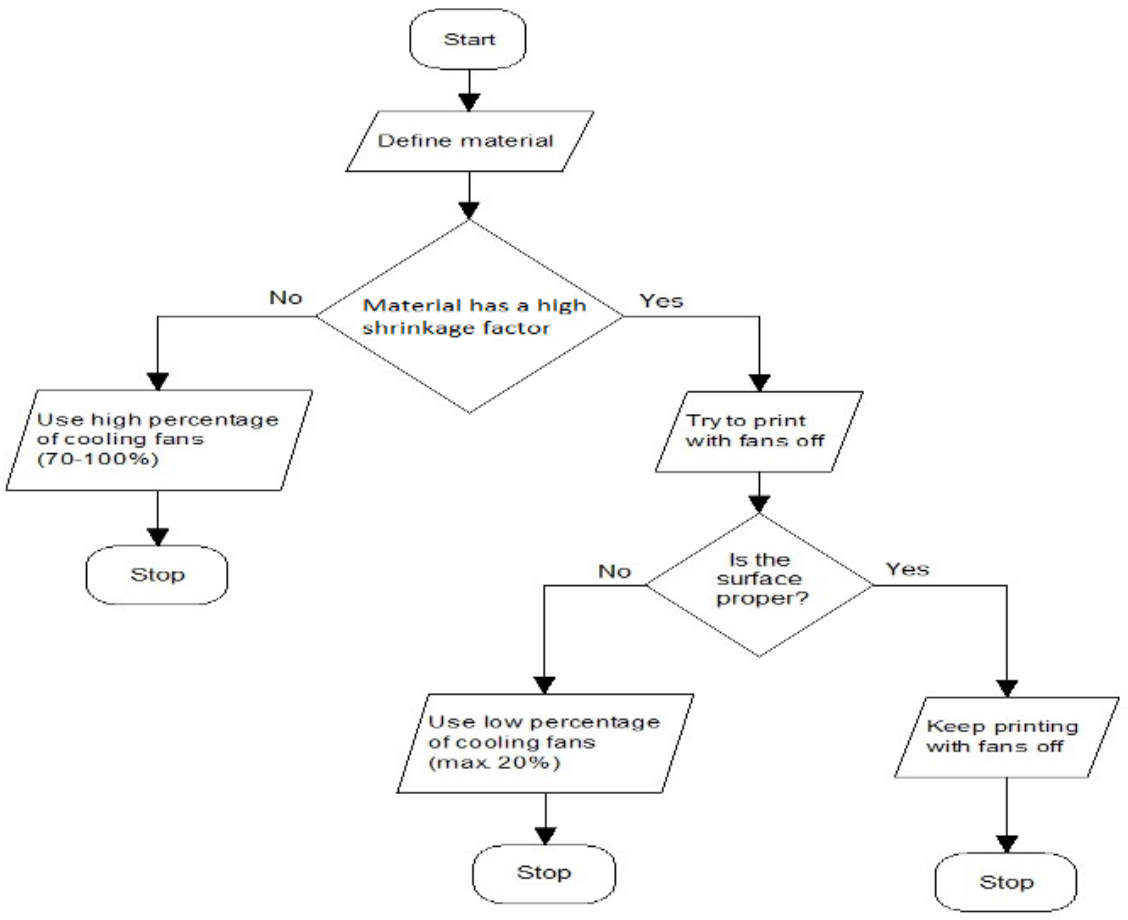

Fig. 5. The cooling rate selection algorithm. 
Material characteristics strongly influence the need for the printout cooling. The first step is analysis of the filament material shrinkage factor [15]. In the case of a low value, the cooling should be more intensive. Depends on the cooling efficiency its value should be between 70 and $100 \%$ of nominal speed. However, if the material has a high shrinkage factor, the printing process should be executed without object cooling. Subsequently, the surface of the printout should be evaluated. Cooling should be turned off if the evaluation of the printout quality is satisfactory and acceptable. In the case of using ABS, printing without cooling provides a better adhesion between layers of the printout by which an increased strength can be achieved. On the other hand, a low percentage of cooling should be used if the quality of the printout is unacceptable. A dozen or so percent of cooling should be used in this case. $20 \%$ of cooling is the value of the upper limit. Above this value, the printout can be deformed during printing.

\section{Summary}

The proper selection of presented, most important parameters of the 3D printing process in FDM technology enables obtaining printouts with exact dimensions and excellent surface quality. Nowadays, FDM technology is not fully automated, but this may change in a few years. The creation of selection parameters algorithm is the first step to achieve this. The proposed algorithm consists of a selection of the optimal mesh density, appropriate diameter of the nozzle hole and the proper value of material flow and percentage of cooling. Because of the fact that the material type has a great influence on certain parameters (e.g. ABS in the case of percentage of cooling) all new materials should be examined separately.

\section{References}

1. 3D printing history, http://3dphoenix.pl/historia.html access: 02.2016 .

2. A brief history of $3 \mathrm{D}$ printing, http://individual.troweprice.com/staticFiles/ Retail/Shared/PDFs/3D_Printing_Infographic_FINAL.pdf, access: 02.2016.

3. P. Siemiński, G. Budzik, Additive Techniques, $3 D$ printing. (in Polish), (Publishing House of Warsaw Polytechnic, Warszawa, 2015)

4. P. Brzeskot, E. Wąsek, Ł. Zatorski, 3d printing - innovations you can rely on (in Polish). Mechanik, 12CD2, 88 197-199 (2015)

5. H. Lipson, M. Kurman, Fabricated - The new world of $3 D$ printing, (John Wiley \& Sons, Inc., Indiana, 2013)

6. A. Kaziunas France, Make: 3D Printing, (Maker Media Inc., 2014)

7. A. Gwiazda, R. Knosala, J. of Mat. Proc. Technol. 64/1-3, 181-188 (1997)

8. B. Evans, Practical 3D Printers - The Science and Art. of 3D Printing, Technology in action (2012)

9. J. Horvath, Mastering 3D Printing, Technology in action, (2014).

10. Description of 3D printing technology, http://www.allaboutlean.com/3d-printing/3dprinting-overview/ access: 08.2016

11. T. Dzitkowski, A. Dymarek, Journal of Vibroengineering 17, 4, 1578-1592 (2015)

12. Opportunities in 3D printing, http://www.marsdd.com/wp-content /uploads/2014/04/MAR-CLT6965_3D-Printing_White_paper.pdf access: 02.2016.

13. Micromart and SB Ltd, The Ultimate Guide to 3 D Printing, (2014)

14. S. Topolska, J. Łabanowski, Mater in Technol. 49/4, 481-486 (2015)

15. Materialise's press materials, http://www.materialise.pl/przeglad-technologii-imaterialow, access: 02.2016. 